Full length article

\title{
Anisotropic crack propagation and deformation in dentin observed by four-dimensional X-ray nano-computed tomography
}

\author{
Xuekun Lu ${ }^{\mathrm{a}, \mathrm{b}}$, Marta Peña Fernández ${ }^{\mathrm{c}}$, Robert S. Bradley ${ }^{\mathrm{a}, \mathrm{d}}$, Shelley D. Rawson ${ }^{\mathrm{a}}$, Marie O’Brien ${ }^{\mathrm{a}}$, \\ Benjamin Hornberger ${ }^{\mathrm{e}}$, Marty Leibowitz ${ }^{\mathrm{e}}$, Gianluca Tozzi ${ }^{\mathrm{c}}$, Philip J. Withers ${ }^{\mathrm{a}, *}$ \\ ${ }^{a}$ Henry Royce Institute, School of Materials, University of Manchester, Manchester M13 9PL, UK \\ ${ }^{\mathrm{b}}$ Electrochemical Innovation Lab, Department of Chemical Engineering, University College London, London WC1E 7JE, UK

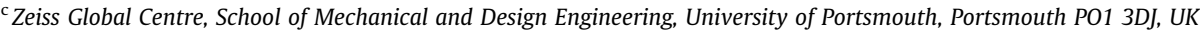 \\ ${ }^{\mathrm{d}}$ Geotek Ltd, 4 Sopwith Way, Daventry NN11 8PB, UK \\ ${ }^{\text {e }}$ Carl Zeiss X-ray Microscopy Inc., Pleasanton, CA, USA
}

\section{A R T I C L E I N F O}

\section{Article history:}

Received 27 April 2019

Received in revised form 20 June 2019

Accepted 24 June 2019

Available online 26 June 2019

\section{Keywords}

Time-lapse imaging

Indentation fracture

Digital image correlation (DIC)

Crack shielding

Ivory

\begin{abstract}
A B S T R A C T
Understanding the cracking behaviour of biological composite materials is of practical importance. This paper presents the first study to track the interplay between crack initiation, microfracture and plastic deformation in three dimensions (3D) as a function of tubule and collagen fibril arrangement in elephant dentin using in situ X-ray nano-computed tomography (nano-CT). A nano-indenter with a conical tip has been used to incrementally indent three test-pieces oriented at $0^{\circ}, 45^{\circ}$ and $70^{\circ}$ to the long axis of the tubules (i.e. radial to the tusk). For the $0^{\circ}$ sample two significant cracks formed, one of which linked up with microcracks in the axial-radial plane of the tusk originating from the tubules and the other one occurred as a consequence of shear deformation at the tubules. The $70^{\circ}$ test-piece was able to bear the greatest loads despite many small cracks forming around the indenter. These were diverted by the microstructure and did not propagate significantly. The $45^{\circ}$ test-piece showed intermediate behaviour. In all cases strains obtained by digital volume correlation were well in excess of the yield strain (0.9\%), indeed some plastic deformation could even be seen through bending of the tubules. The hoop strains around the conical indenter were anisotropic with the smallest strains correlating with the primary collagen orientation (axial to the tusk) and the largest strains aligned with the hoop direction of the tusk.
\end{abstract}

\section{Statement of Significance}

This paper presents the first comprehensive study of the anisotropic nature of microfracture, crack propagation and deformation in elephant dentin using time-lapse X-ray nano-computed tomography. To unravel the interplay of collagen fibrils and local deformation, digital volume correlation (DVC) has been applied to map the local strain field while the crack initiation and propagation is tracked in real time. Our results highlight the intrinsic and extrinsic shielding mechanisms and correlate the crack growth behavior in nature to the service requirement of dentin to resist catastrophic fracture. This is of wide interest not just in terms of understanding dentin fracture but also can extend beyond dentin to other anisotropic structural composite biomaterials such as bone, antler and chitin.

(C) 2019 The Authors. Published by Elsevier Ltd on behalf of Acta Materialia Inc. This is an open access article under the CC BY license (http://creativecommons.org/licenses/by/4.0/).

\section{Introduction}

It is well known that considerable toughness is achieved in many biological structural materials (e.g. bone [1], dentin [2,3], beetle cuticle [4], lobster [5], and nacre [6]) through the use of interfaces and a hierarchical architecture [7] as a means of hinder-

\footnotetext{
* Corresponding author.

E-mail address: p.j.withers@manchester.ac.uk (P.J. Withers).
}

ing crack growth. In particular, the crack-resistance of dentin, as the major constituent of teeth and tusk, is a subject of considerable biomechanical interest. Here our aim is to look at the fracture of elephant dentin at the microscale to study the underlying physical processes as a function of sample orientation. Insights into the interplay between the microstructure and the crack behavior will help us to have a better understanding of the crack-tip shielding mechanisms and could potentially inspire biomimetic design [8]. 

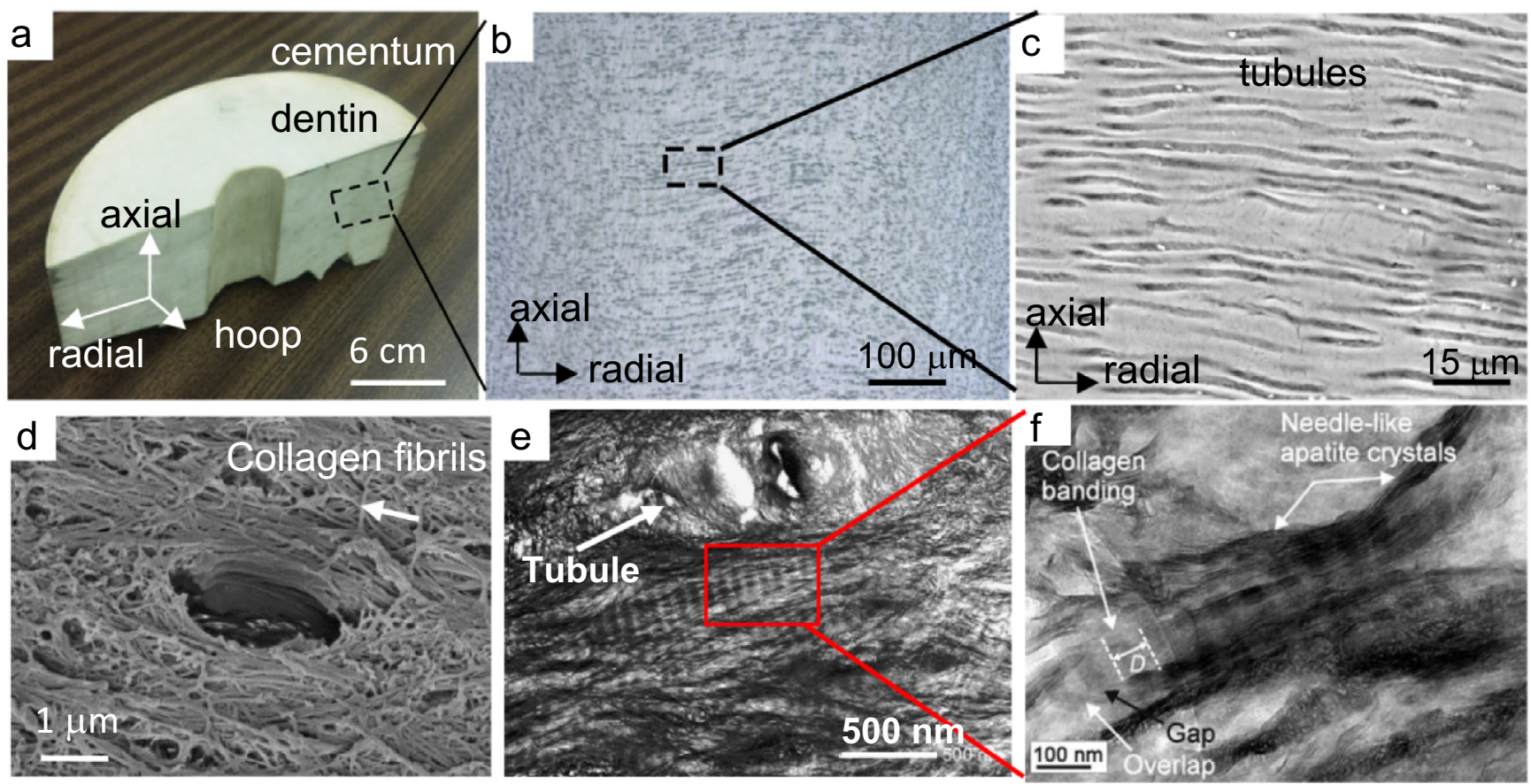

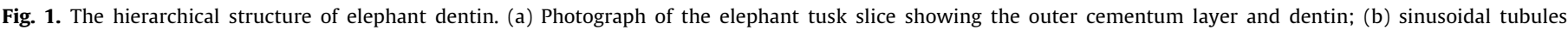

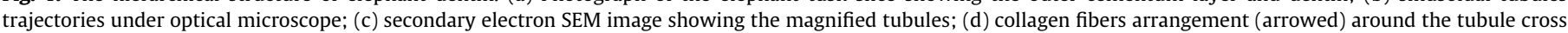

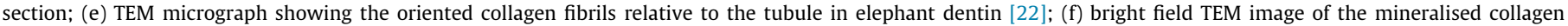
showing the apatite crystals [23]

Elephant dentin (tusk, Fig. 1) is studied in part because it is an interesting anisotropic material, in part because it has many chemical and structural similarities to human dentin, bones and antlers [9-11] and in part because it is possible to obtain nominally identical samples from a single tusk thereby eliminating sample to sample variation. The hierarchical microstructure of elephant dentin is well studied. At the mesoscale elephant dentin includes dentinal tubules that run radially from the central pulp to the periphery of the dentin following a wavy trajectory with a periodicity of $\sim 1 \mathrm{~mm}[12,13]$ (Fig. 1b). Compared to human dentin, which has tubules of approximately circular cross-section, the $\sim 5 \mu \mathrm{m}$ diameter tubules in elephant dentin are elliptical with the semimajor axis oriented parallel to the length of the tusk (Fig. 1d and e). At the microscale, the mineralised collagen fibers are arranged essentially in cylindrical layers perpendicular to the tubules. By contrast to human dentin which has the fibrils oriented randomly within the plane of the layers in tusk they tend to be oriented within $\pm 15^{\circ}$ of the axial direction $[13,14]$ (see Fig. 1d). At the nanoscale, each of the mineralised collagen fibers is composed of bundles of collagen fibrils, which are themselves made up of collagen molecules and Mg-rich hydroxyapatite needles [15-20] (Fig. 1e and f): the highly mineralized hydroxyapatite (HAP) improves the stiffness, while the collagen provides toughness [21].

The fracture properties of human, bovine and elephant dentin have been widely studied [24-27]. It has been found that the crack growth is highly anisotropic in these biological composite materials. For elephant dentin the critical fracture toughness $K_{I C}$ is at least $50 \%$ higher for cracks propagating parallel to the long axis of the dentinal tubules compared to those perpendicular to the tubules $[26,28,29]$. The anisotropy of fracture toughness is attributed to the underlying crack-tip shielding mechanisms. Lu et al. [14] observed significant uncracked-ligament bridging and a multiple finger-like crack front morphology by non-destructive highresolution 3D X-ray computed tomography $(\mathrm{CT})$. These extrinsic shielding phenomena were mainly found for cracks growing in the radial-axial plane of the tusk, when the crack propagates parallel to the tubules. Understanding the relationship between the local microstructure and the various shielding mechanisms has been the focus of a great deal of research [28,30,31].

Nanoindentation has been used extensively to investigate the mechanical properties of teeth and to correlate this with the underlying microstructures [32-36]. It has been found that the main cause of the elastic anisotropy is the arrangement of hydroxyapatite crystals along or perpendicular to the indentation direction [37]. Hydrated dentin has been found to have a significantly lower hardness compared to dehydrated dentin but similar energy absorption [38]. Nanoindentation has also been used to provide local fracture toughness measurements [39-41], which differ significantly from those measured using conventional test methods (i.e. compact tension). Even for the same indentation test, different empirical equations can lead to a large degree of scatter [42-44]. Consequently, the indentation method is often used as a semiquantitative way to rank the toughness of different materials, rather than for absolute property measurement [45]. Nevertheless, indentation has been found to be a useful means of studying the microfracture behavior, crack-tip shielding and their anisotropy [46].

X-ray computed tomography (CT) is being used increasingly to non-destructively inspect the $3 \mathrm{D}$ micro-structure of materials $[47,48]$. It has been applied to study the 3D crack morphologies and propagation below the surface of dentin [47,49,50], helping to elucidate the shielding mechanisms and fracture anisotropy. In particular, the 'finger' crack front morphology observed by Lu et al. [14], which extends approximately $400 \mu \mathrm{m}$ behind the crack-tip across the entire sample thickness and is a major contributor to crack-tip shielding but could not be seen by conventional cross-sectioning. Another advantage of CT data over optical microscopy is the ability to study the evolution of cracks through timelapse sequences, as well as to use digital volume correlation (DVC) to obtain 3D full-field strain maps. DVC, which is the 3D analogue 
of digital image correlation (DIC), has been used to study the straining of biological tissues such as bone [51,52] as well as dimensional changes in dentin during hydration/dehydration [53].

This study looks at the interplay between crack initiation, microfracture and plastic deformation in relation to the local microstructure, namely the tubules and collagen fibers using in situ 3D X-ray nano-CT indentation. In order to examine the effect of tubule orientation samples are indented using a customised nano-mechanical test rig [54] in three different orientations $\left(0^{\circ}\right.$, $45^{\circ}$ and $70^{\circ}$ to the long axis of the tubules). Our aim is to develop a better understanding of the crack-tip behaviour in relation to the dentin microstructure during the early stages of crack growth. Absorption and phase contrast scans were conducted at each load step to retrieve the tubule and crack morphologies, respectively. In this way the crack-tip strain field was then mapped by applying DVC to the image sequences to quantify the anisotropy of the deformation and fracture.

\section{Materials and experimental methods}

\subsection{Test-piece preparation}

Mature African elephant tusk was used in this study; the material having been made available by the UK Customs House, ethically and legally, solely for the purpose of scientific research. The coordinate system relative to the tusk is shown in Fig. $2 \mathrm{a}$ and the orientation of the tubules clearly shown in Fig. $2 \mathrm{~b}$. To investigate the anisotropy and micro-mechanisms of crack growth, three test-pieces were prepared each having a different orientation of tubules relative to the loading axis of the indenter: $0^{\circ}$ (Fig. 2c), $45^{\circ}$ (Fig. 2d) and $70^{\circ}$ (Fig. 2e).

\subsection{Time-lapse $X$-ray nano-CT}

A novel nano-mechanical test stage was developed for integration into the Xradia Ultra series X-ray microscopes [54]. The assembly and experimental setup is shown in Fig. 3. The fixture includes a piezo-mechanical actuator, a load cell (force sensor) and a cone-shaped indenter above a flat-headed pin, where the test-piece is mounted. The whole assembly is mounted on the $\mathrm{X}$-ray microscope stage, which rotates for tomographic data collection. The load was applied under displacement control in steps of $1 \mu \mathrm{m}$. The test-piece was held in position to allow the load to stabilise before each scan. The diamond indenter tip is semi X-ray transparent to allow the observation of the tip-sample interface. Fig. 3c-e shows the projections of the three test-piece orientations using phase contrast mode. The orientations of the tubules are clearly visible. Gold balls ( $2 \mu \mathrm{m}$ diameter) were placed on the sample surface for post-correction of any sample drift during the scan.

The nano-CT scans were acquired on a Zeiss Xradia 810 Ultra Xray microscope at the Henry Moseley X-ray Imaging Facility. This system uses $5.4 \mathrm{keV}$ quasi-monochromatic X-rays and generates images with a spatial resolution (as against pixel size) of $150 \mathrm{~nm}$. Test-pieces were manually polished to a truncated cone shape to achieve a diameter of approx. $50 \mu \mathrm{m}$ at the top and $1 \mathrm{~mm}$ at the bottom. The field of view is $64 \mu \mathrm{m}$ with projections collected every $90 \mathrm{~s}$ using a $1 \mathrm{k}$ by $1 \mathrm{k}$ pixel 16-bit camera (effective voxel size of $64 \mathrm{~nm}$ ). Each projection was separated by an angle of $0.25^{\circ}$ giving

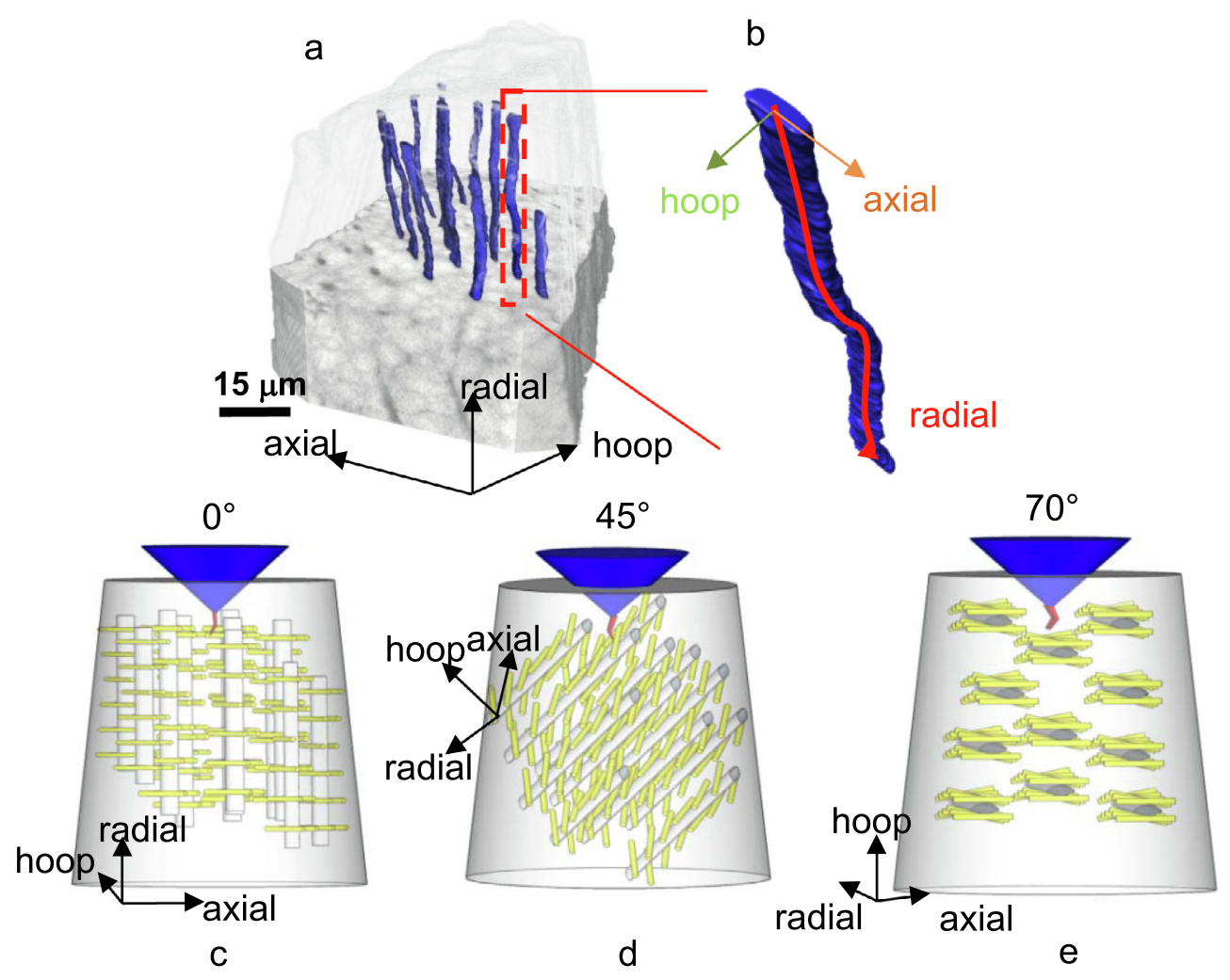

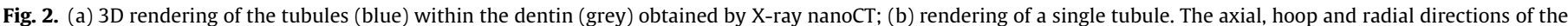

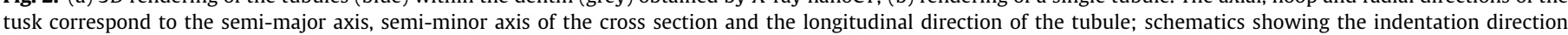

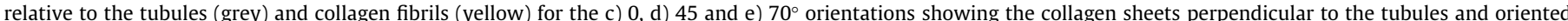

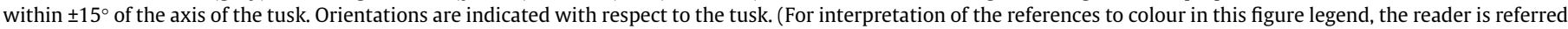
to the web version of this article.) 

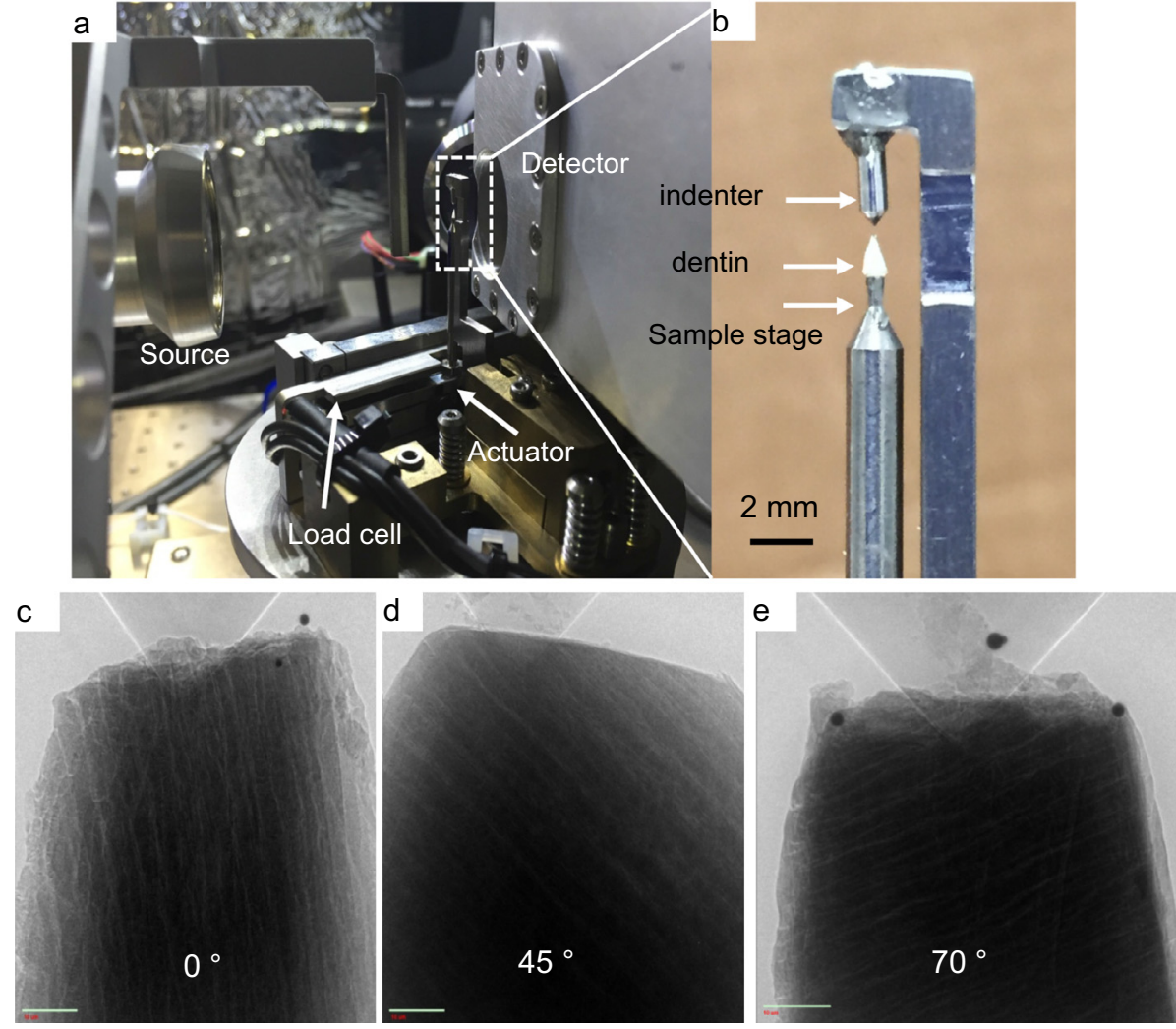

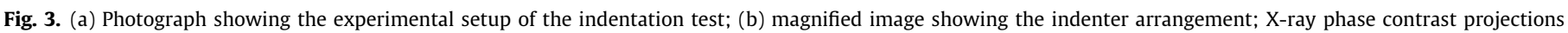
(radiographs) for the c) $0^{\circ}$, d) $45^{\circ}$ and e) $70^{\circ}$ oriented test-pieces (scalebar: $10 \mu \mathrm{m}$ ).

721 projections over a $140^{\circ}$ scan. This limited angle scan is $40^{\circ}$ less than a normal $180^{\circ}$ scan (quasi-parallel beam) because the X-ray incident beam was blocked by the mechanical rig from $-70^{\circ}$ to $-90^{\circ}$ and $70^{\circ}$ to $90^{\circ}$. However, reconstructions using full $180^{\circ}$ (unobstructed) and partial $140^{\circ}$ projections were compared and no visible difference was observed between the reconstructed images except for slight streak artefacts at the outer edge of the sample. Thus the limited angle scan has little influence on the data analysis nor on the detectability of the cracks. Absorption contrast $(\mathrm{ACT})$ and phase contrast $(\mathrm{PCT})$ tomography scans were conducted at each load step as ACT mode provides good contrast between the dentin matrix and the tubules, while the crack is sharper in PCT mode. A filtered-back projection algorithm $[55,56]$ was used for the reconstruction and the 3D volume was visualised using Avizo V8.0 software.

\subsection{Strain measurement by digital volume correlation (DVC)}

Digital volume correlation (DaVis v8.4, LaVision, Germany) was carried out on each of the CT volume image sequences to map the local deformation under the indenter tip. DaVis software is based on a local approach operating on the intensity values (grey-scale) of 3D images, which has been extensively used in hard tissue biomechanics $[52,57,58]$. Details of the operating principles and algorithm are detailed elsewhere [59]. The volumes were correlated using a multi-pass scheme with a final sub-volume of 48 voxels $(\sim 3 \mu \mathrm{m})$, reached via predictor passes using sub-volumes of $144,72,64$ and 56 voxels with a $0 \%$ overlap. Displacement vectors were derived by maximising the zero-mean normalised correlation coefficient and sub-volumes with a correlation coefficient below 0.6 were removed from the resultant vectors to avoid artefacts due to poor correlation. Empty spaces in the data were then filled with interpolated vectors and the strain field was obtained by differentiation of the displacement vectors. Random errors on the DVC-computed displacements did not exceed $0.3 \mu \mathrm{m}$, whereas the precision [60] of the strain components were found to be approx. $300 \times 10^{-6}$. The strain field tensor is expressed in polar coordinates (axial $\left(\varepsilon_{z}\right)$, radial $\left(\varepsilon_{\rho}\right)$ and hoop $\left(\varepsilon_{\theta}\right)$ ) relative to the conical indenter.

\subsection{Fracture surface observation by scanning electron microscopy (SEM)}

A $2 \times 2 \mathrm{~mm}$ fracture surface was prepared from the elephant dentin, such that the fracture surface was perpendicular to the major axis of the tubules. The sample was decalcified in 5\% phosphoric acid (Sigma-Aldrich, Gillingham, UK) for 30 s before dehydration. The sample was dehydrated through ascending grades of ethanol, followed by $100 \%$ acetone (Merck, Gillingham, UK), 50:50 acetone/Hexamethyldisilazane (HDMS) (Sigma-Aldrich, Gillingham, UK) and 100\% HDMS, then finally stored within a desiccator for $24 \mathrm{~h}$. The fracture surface was then sputtered with a $5 \mathrm{~nm}$ thick gold coating, followed by SEM imaging using an Ultra55 SEM (Zeiss, Oberkochen, Germany).

\subsection{Statistical analysis}

For each of the three orientations, at least five repeat nanoindentation tests were conducted. The variance of the experiment data and comparison between groups were examined using the mean and error bars representing the standard deviation performed in Origin 2015. 


\section{Results}

\subsection{Indentation curves}

The indentation response of the three differently oriented samples is shown in Fig. 4. The indentation curves are broadly similar except for the maximum load sustained which is significantly lower for the $0^{\circ}$ orientation, with the $70^{\circ}$ orientation slightly higher than the $45^{\circ}$ orientation. Moreover, it is noted that all the three types of test-pieces display a linear elastic loading regime, followed by an evident yielding process, which implies the microfracture initiation and crack propagation in dentin.

\subsection{Time-lapse imaging of crack growth}

The damage sequences are shown in Figs. $5-7$ for the $0^{\circ}, 45^{\circ}$ and $70^{\circ}$ orientations respectively. For the $0^{\circ}$ test-piece, the horizontal orthoslices (A1-3) in Fig. 5 show that cracks initiate from the indenter and propagate initially parallel to the length of the tusk linking up with microcracks emanating from the tubules parallel to their semi major axes and parallel to the plane of the collagen fibrils (i.e in the axial-radial plane of the tusk). Fig. 5 B1-3 shows the crack behaviour in a longitudinal section: the crack can be seen to propagate downward from the indenter tip along the tubules (cyan arrow in Fig. 5 B2), but then arrests. In C1-3 a shear crack is evident (yellow arrow) that runs across the tubules. The 3D crack morphology is shown in Fig. 8 a for the $0^{\circ}$ test-piece. The two types of cracks can be distinguished with the shear crack (rendered yellow) ultimately causing the catastrophic failure (c.f. Fig. 5 C2 and C3).

For the sample indented at $45^{\circ}$ to the tubules, it is clear from Fig. 4 that much larger loads must be applied than for the $0^{\circ}$ case before cracking and failure. Accordingly the dentin accommodates a much more significant indentation before failure. While extensive cracking occurs below $50 \mathrm{mN}$ for the $0^{\circ}$ case, tiny cracks only start to initiate at approx. $80 \mathrm{mN}$ (Fig. $6 \mathrm{~A} 1$ ). The micro-cracks tend to propagate laterally along the semi-major axis of the tubules/collagen fibrils (i.e. along the axial direction of the tusk), as delineated by the yellow arrow in Fig. 6 A2. By the time the load reaches $150 \mathrm{mN}$, not only is there significant crack growth in the axial direction (yellow arrow), but there are also cracks circumferential to the indenter (cyan arrow). Both of these two types of cracks follow the semi-major axis of the tubules. However, no cracks are observed parallel to the hoop direction (green axis) of the tusk (i.e. along the semi-minor axis of the tubule cross section). The lateral views in Fig. 6 B1-3 show lots of small cracks parallel to the semi-major axis of the tubule cross section. However, in contrast

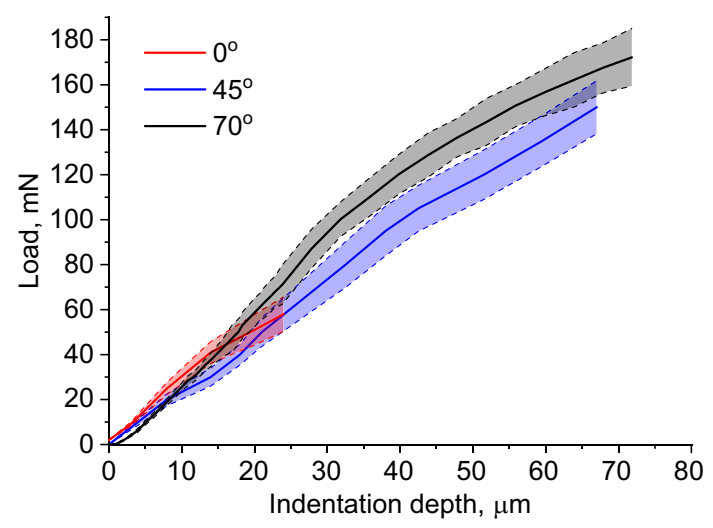

Fig. 4. Load vs. indentation depth relationship for three test-piece orientations. The shaded-regions represent the uncertainty for each orientation. to the $0^{\circ}$ case very few micro-cracks are observed in the $y z$ plane (Fig. 6 C1-3) before the formation of a large shear crack cutting through the tubules transversely at the maximum load. The 3D morphology of the cracks can be appreciated in Fig. $8 \mathrm{~b}$.

For the sample indented at $70^{\circ}$ to the tubules, a very different response is evident (Fig. 7 A1-3); very tiny cracks are generated radial to the indenter especially in lobes normal to the $y$ direction. The length and number of these cracks do not increase significantly with loading. These are also evident in the $y-z$ slices ( $C$ series in Fig. 7). Higher load increments do not cause these cracks to extend further, but rather cause them to open further. The lateral views of the $x z$ plane show that a short crack initiated from the indenter tip in the hoop direction of the tusk stops propagating despite the increasing load (Fig. 7 B1-3). In the $y z$ plane, two types of crack can be seen: one set in the hoop direction (red arrow in Fig. $7 \mathrm{C} 3$ ) and the other in the axial direction of the tusk, following the semi-major axis of the tubule cross section (green arrow in Fig. 7 C3). Upon increasing the indenting load, the growth of the hoop crack is slow so that only the axial crack is propagating.

The very different cracking behaviour is also evident from the 3D rendering in Fig. 8c showing many very short cracks that do not appear to propagate being localised to the vicinity of the indenter tip. They divert from the indentation direction towards the semi-major axis of the tubules (axial direction of the tusk). Video 1 exhibits the 3D microstructure of elephant dentin (using $45^{\circ}$ as an example) and the dynamic crack propagation under indentation experiment.

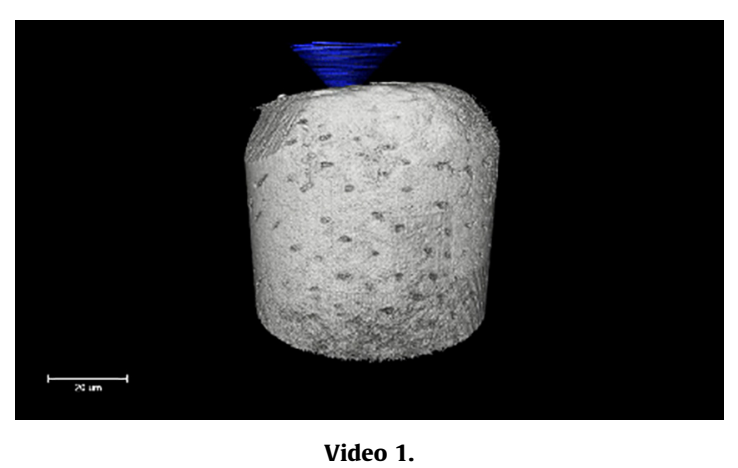

Taken together these results confirm the highly anisotropic nature of elephant dentin with most of the cracks tending to grow along the semi-major axis of the tubules (length of the tusk) and especially in a plane that also includes the long axis of the tubules (in many cases linking up pre-existing microcracks radial-axial emanating from the tubules). No cracks appear to grow in the hoop direction of the tusk.

\subsection{Crack-tip strain field mapping}

It is clear from the sequential cross-sectional images in Fig. 9 that considerable plastic deformation occurs immediately under the indenter tip in the $0^{\circ}$ test-piece despite its propensity for large cracks. It is noteworthy that a crack initiates in the region where the plastic shear is greatest (evidenced by the bending of the tubule). This shear crack ultimately results in catastrophic failure.

In order to better understand the deformation that takes place under the indenter tip, digital volume correlation (DVC) has been used to map the strain fields quantitatively. Unsurprisingly the DVC strain maps consistently show a general increase in compressive 

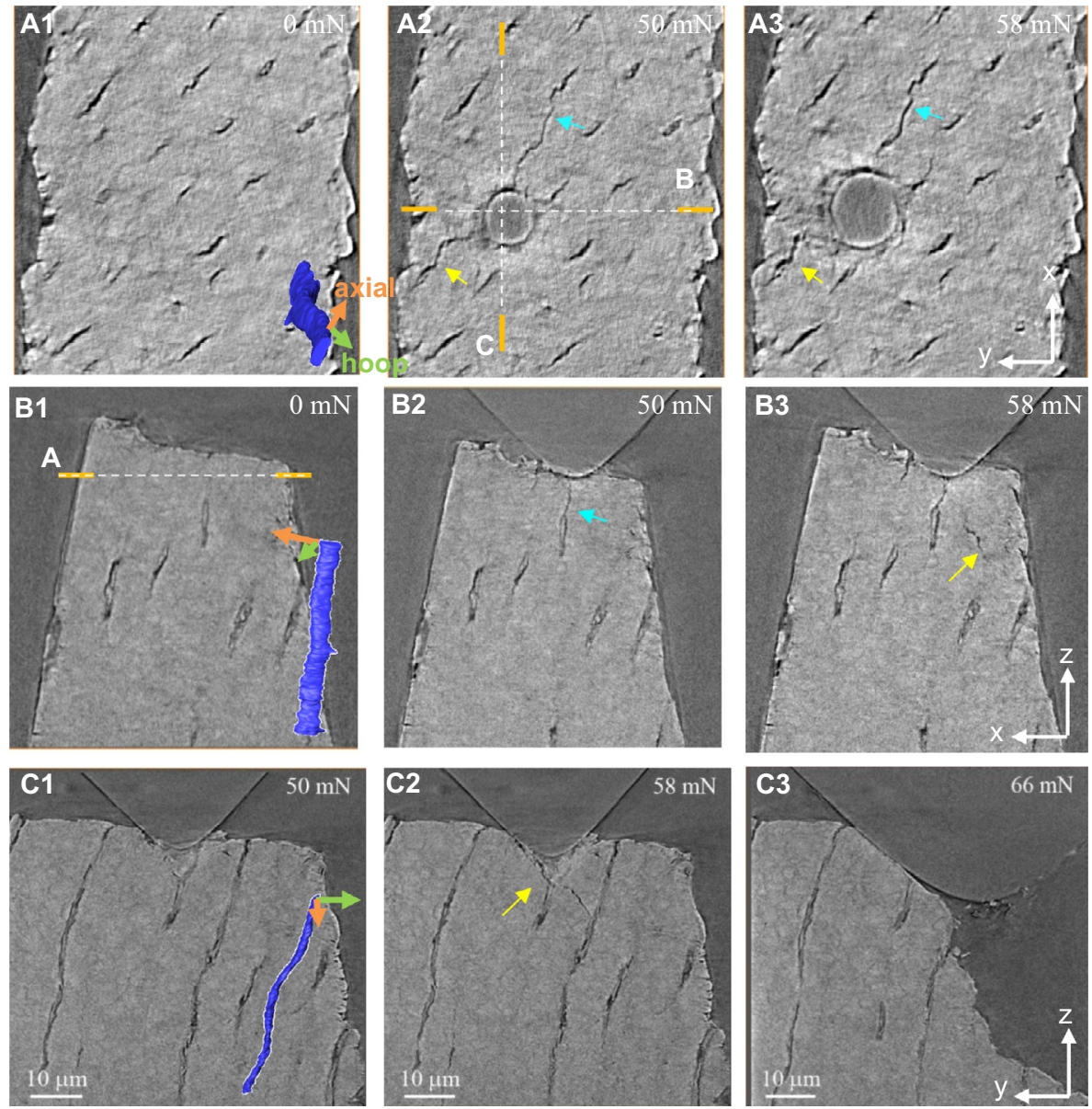

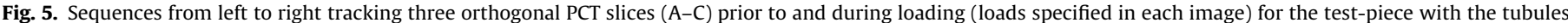

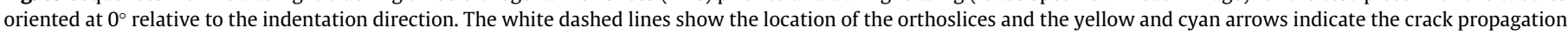

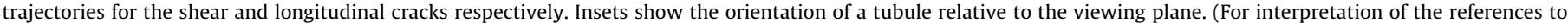
colour in this figure legend, the reader is referred to the web version of this article.)

strain with load for all the test-pieces along the axial direction relative to the indenter $\left(\varepsilon_{z}\right)$, irrespective of the tubule orientation as shown in Fig. 10. The axial strains are essentially axially symmetric and reflect the profile of the conical indenter profile. These results confirm that extensive plastic deformation has taken place, given that the yield strain was previously found to be around $0.9 \%$ for hydrated and dehydrated elephant dentin [14]. A closer inspection of the results reveals that the build-up of compressive strain in the $0^{\circ}$ test-piece is less extensive compared to the $45^{\circ}$ test-piece before catastrophic failure just above $58 \mathrm{mN}$. The $70^{\circ}$ test-piece displays the lowest compressive strain among all the three orientations. This difference is closely associated with the collagen orientations relative to the tubules and the indention axis as discussed later.

The hoop strains $4 \mu \mathrm{m}$ below and above the indenter are shown in Fig. $11 \mathrm{a}$ and $\mathrm{b}$ respectively for the $0^{\circ}, 45^{\circ}$ and $70^{\circ}$ cases. The hoop strains, in contrast to the axial strains, reflect to anisotropy of the dentin. It is clear in Fig. 11 that for the $0^{\circ}$ sample the hoop strains are much more significant perpendicular to the semi-major axis of the tubules rather than along it. This is in line with the fact that the collagen fibrils lie parallel to the semi major axis making this direction much stiffer. In addition it is clear that the hoop strain has been accommodated by microcracks that emanate from the tubules along the semi-major axis (radial-axial plane of the tusk) ahead of the indenter. As a result the high tensile strain regions (red zones marked with a ' $\mathrm{T}$ ') are associated with mode I cracks cleaving the dentin along the tubule major axis direction. For the $45^{\circ}$ case the hoop tensile strain is also highly anisotropic being most tensile where the tensile hoop stress can open cracks approximately parallel to the semi-major axis of the tubules (parallel to the collagen fibrils). For the $70^{\circ}$ case, the largest tensile hoop strains (top-left and bottom right of the image) do not appear to correspond to the locations where the cracks initiate in Fig. $7 \mathrm{~A}$ although radial cracks do appear to proliferate around most of the circumference of the indenter in Fig. 7 A3. Unsurprisingly above the indenter tip much more extensive cracking is evident (Fig. 11b), with the cracks mainly associated with the high tensile hoop strain regions and for the $0^{\circ}$ and $45^{\circ}$ test-pieces at least in locations being oriented radial to the indenter in locations where the collagen fibrils are oriented radially.

\section{Discussion}

This study has examined crack initiation, microfracture and plastic deformation in three types of test-pieces with different orientations in ivory tusk to understand their interplay with the tubule and collagen fibril arrangement using in situ 3D X-ray nano-computed tomography (nano-CT). The long axis of the collagen fibrils aligns approximately with the axis of the tusk with the oscillation of $\pm 15^{\circ}[12,14]$ in the hoop plane. They also oscillate by $\pm 5^{\circ}$ in the radial plane [13], which makes the mechanical properties (fracture toughness, plastic deformation, bending and tensile strength) of the elephant tusk significantly anisotropic. This is in contrast to the human dentin in which the collagen fibrils are 

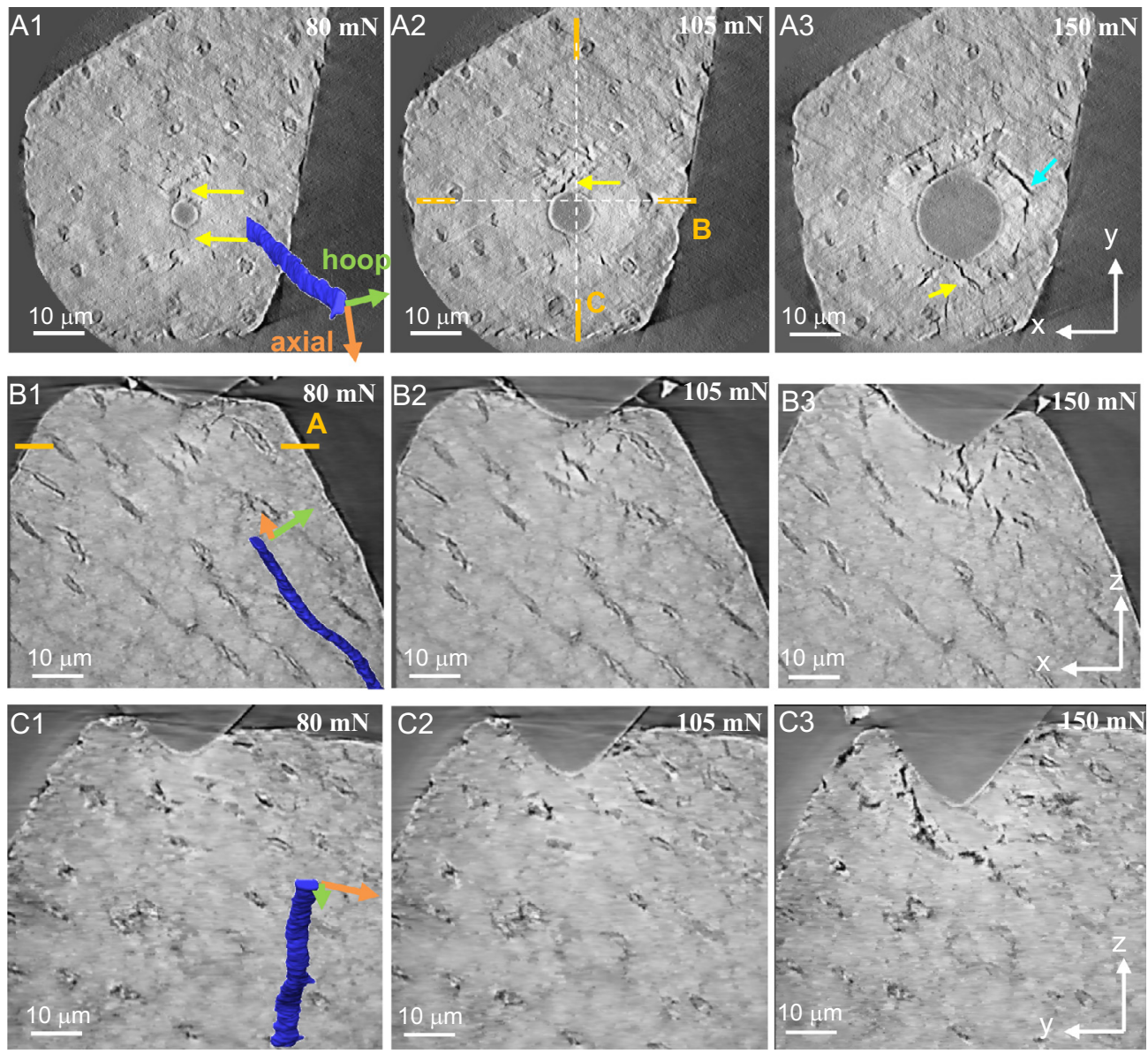

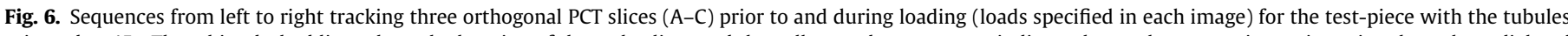

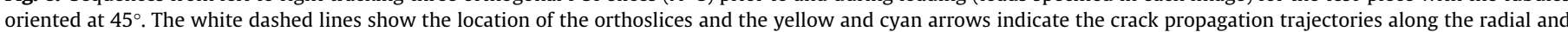

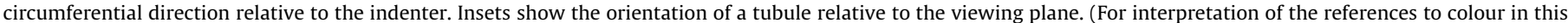
figure legend, the reader is referred to the web version of this article.)

randomly oriented in a plane perpendicular to the tubule axis [61]. In concert with the alignment of the collagen fibrils with the axis of the tusk, the tubules are lenticular (see Fig. 1d and e) with the semi-major axis aligned with the collagen fibrils. This means that microcracks can easily form in the radial-axial plane. The network of collagen fibrils and tubule microcracking in tusk dentin plays an important role in intrinsic and extrinsic crack-tip shielding mechanisms $[14,26,28,29]$.

For the $0^{\circ}$ test-piece, two types of cracks are observed in this study: one follows the tubules in the axial-radial plane of the tusk (yellow crack in Fig. 12) along the semi major axis of the tubules and the other cuts across them due to shear (cyan crack in Fig. 12). It is clear that the propensity of the dentin to crack in the radial-axial plane determines the path of both types of crack and is responsible for the low resistance of our sample to cracking and because of the small sample size the shear crack soon runs out of the sample giving catastrophic failure in our case. For a larger sample the cracks could ultimately arrest. This orientation is equivalent to radial indentation of the tusk and could lead to axial splitting of the tusk.

For the $70^{\circ}$ test-piece, the collagen fibrils are largely aligned perpendicular to the indenting direction, providing high resistance to cleavage failure around the indenter (Fig. 12). This explains why the very few vertical cracks in tusk hoop direction stop their growth (yellow arrow in Fig. 7 C2-C3) and tiny cracks show tendency to be deflected horizontally towards the radial-axial plane direction. This is in good agreement with our previous observa- tions of large crack deflections $\left(>70^{\circ}\right)$ for compact tension samples where cracks are introduced in the radial-hoop plane [14]. This is different from what was inferred from a previous study that the crack would follow a zig-zag trajectory due to the oscillation of the collagen fibrils [13]. The alignment of the collagen fibrils effectively helps to accommodate the strain energy and provides significant intrinsic crack-tip shielding in the hoop direction (Fig. 11). As a result, no major crack is observed in this test-piece, instead, distributed short cracks are formed (Fig. 8c), which are advantageous in that they absorb energy, mitigate stress concentration and inhibit catastrophic failure. Apart from intrinsic shielding, crack deflection is regarded as an important extrinsic shielding mechanism as the cracks are directed to a plane of much lower driving force and the fracture mode is changed from Mode I (tension) to Mode II (shear) or mix mode (Mode I + Mode II). Compared to the $0^{\circ}$ testpiece, the shear crack here will experience much higher resistance due to the arrangement of the oscillating-plywood architecture of the collagen fibrils.

The $45^{\circ}$ test-piece can be regarded as a combination of the fracture behaviour of the other two orientations showing: shear cracking (cyan) and axial cracking (yellow) of the tusk along the major axis of the tubule cross section, which is caused by either longitudinal compressive stress (Figs. 9 and 10) or stress along the minor axis of the tubule in the tusk hoop direction (Fig. 11). As a consequence, the crack morphology is different from the other two: localised microfracture is observed to initialise across multiple tubules in the manner of shear and axial cracking (yellow and cyan arrow in 

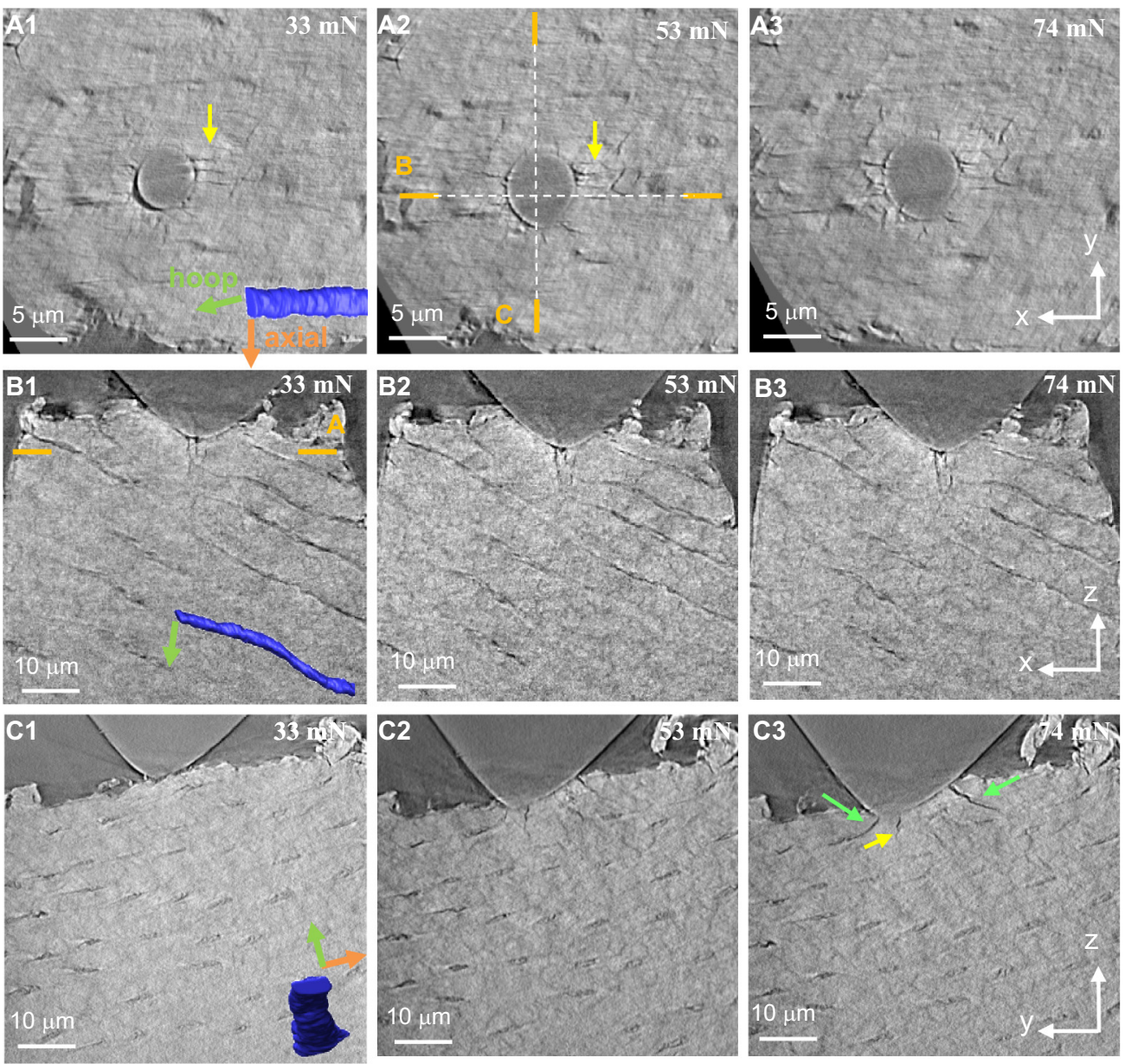

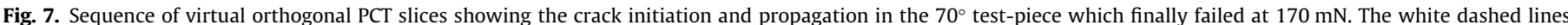

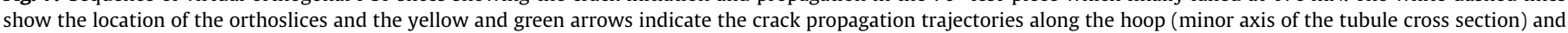

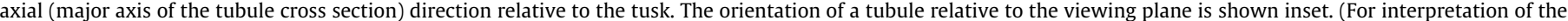
references to colour in this figure legend, the reader is referred to the web version of this article.)

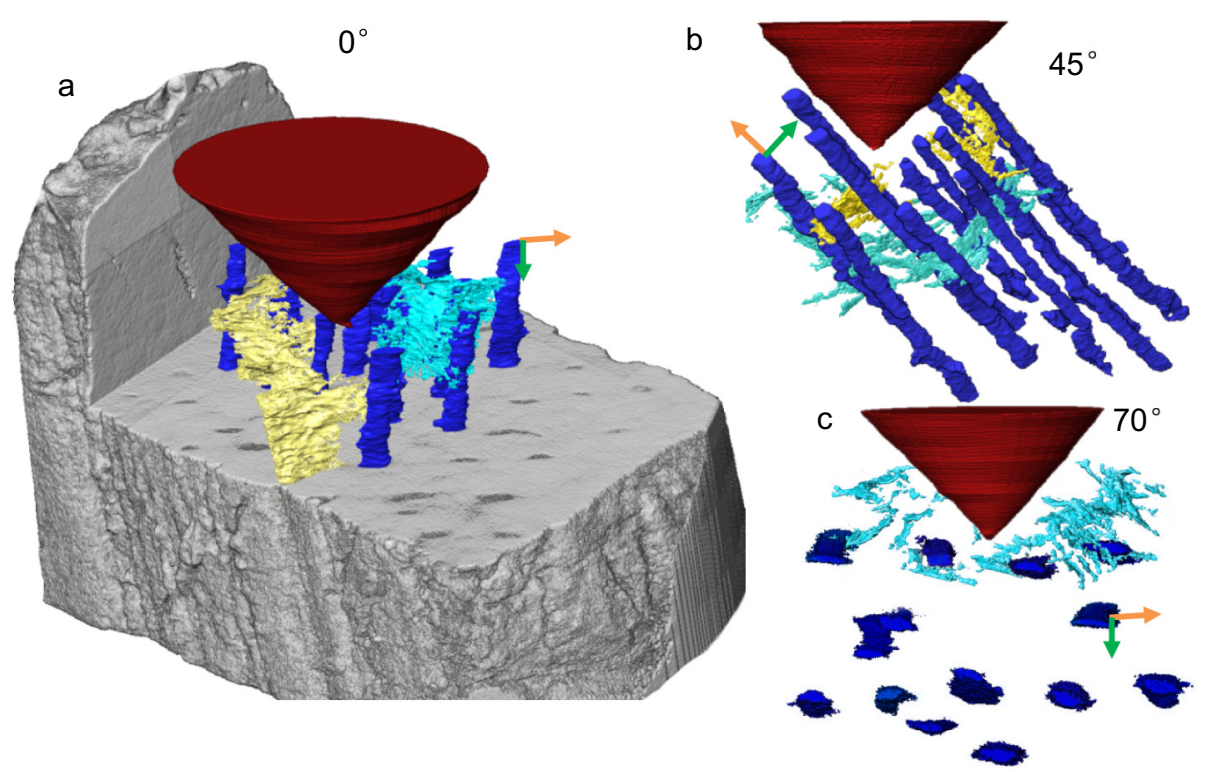

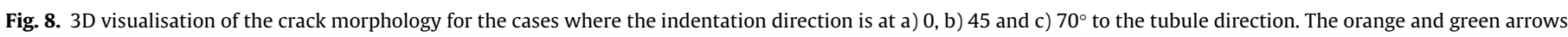

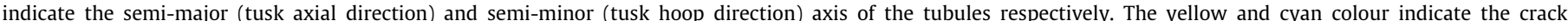

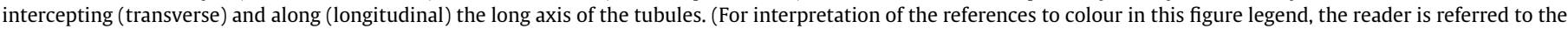
web version of this article. 

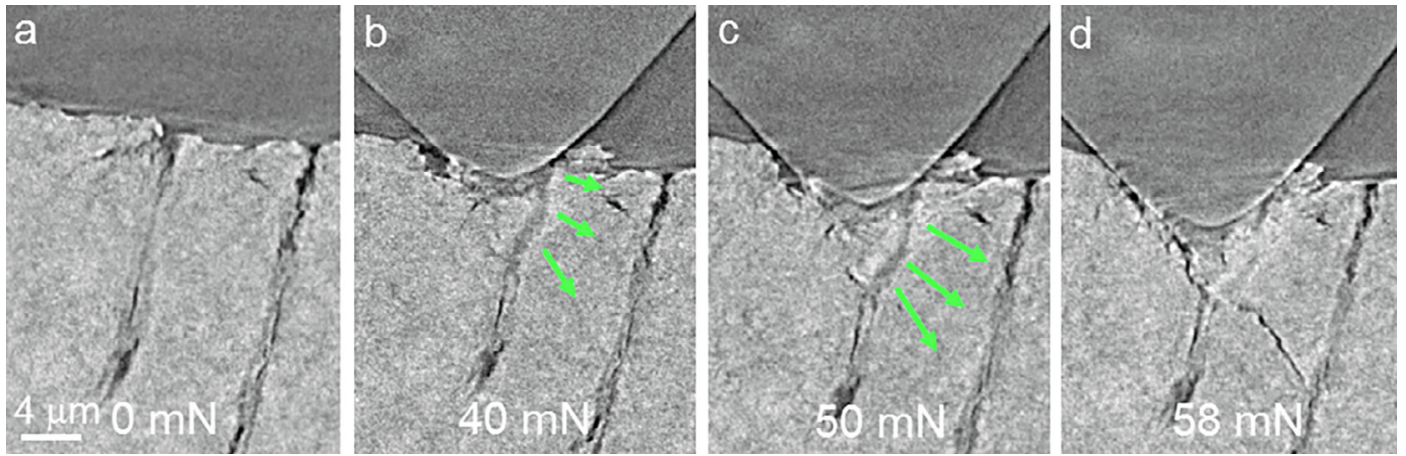

Fig. 9. Cross sectional image sequence showing the local plastic deformation under the indenter as a function of the applied load for the $0^{\circ}$ test-piece.
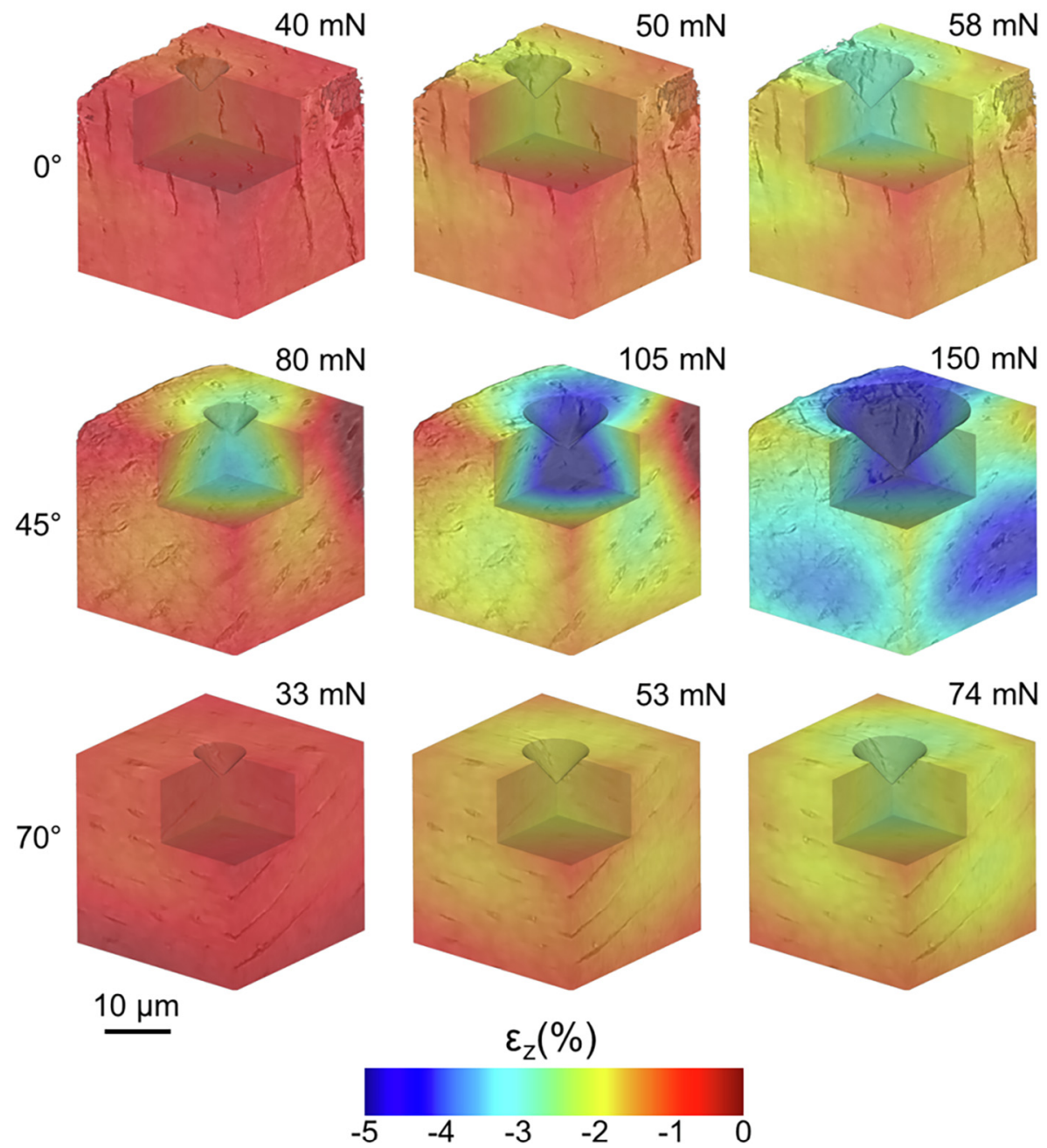

Fig. 10. 3D full-field axial compressive strain $\left(\varepsilon_{z}\right)$ distribution as a function of the applied load for the three differently oriented test-pieces $\left(0^{\circ}, 45^{\circ}\right.$ and $\left.70^{\circ}\right)$.

Fig. 12 respectively) at low loads $(30 \mathrm{mN})$, which then propagates by coalescing with similar cracks nearby. The existence of microcracks, altogether with the efficacy of collagen fibrils, contribute to a much higher sustainable hoop tensile strain in the $45^{\circ}$ testpiece compared to $0^{\circ}$ test-piece. It is the extrinsic (bridging, deflection, micro-cracking) and intrinsic (collagen fibrils deformation) shielding mechanisms that ensure sub-critical propagation of the cracks, dissipating the energy as the crack proceeds.

It is worth pointing out that this study was conducted on dry instead of hydrated dentin for three reasons: 1 ) the whole experi- ment took up to five days thus any pre-hydrated dentin would dry out during the experiment; 2) water could cause the test-piece to drift while it is drying and undermine the sharpness of the reconstructed data; 3 ) the refractive effect of water on X-ray will further affect the detectability of tiny cracks. However, the phenomena observed here are still valid for hydrated dentin, which is known to have higher fracture toughness than the dry one. In other words, while the $45^{\circ}$ and $70^{\circ}$ will have more effective crack shielding compared to the $0^{\circ}$ test-piece, the crack morphology, propagation propensity and anisotropic behaviour will be the same. 


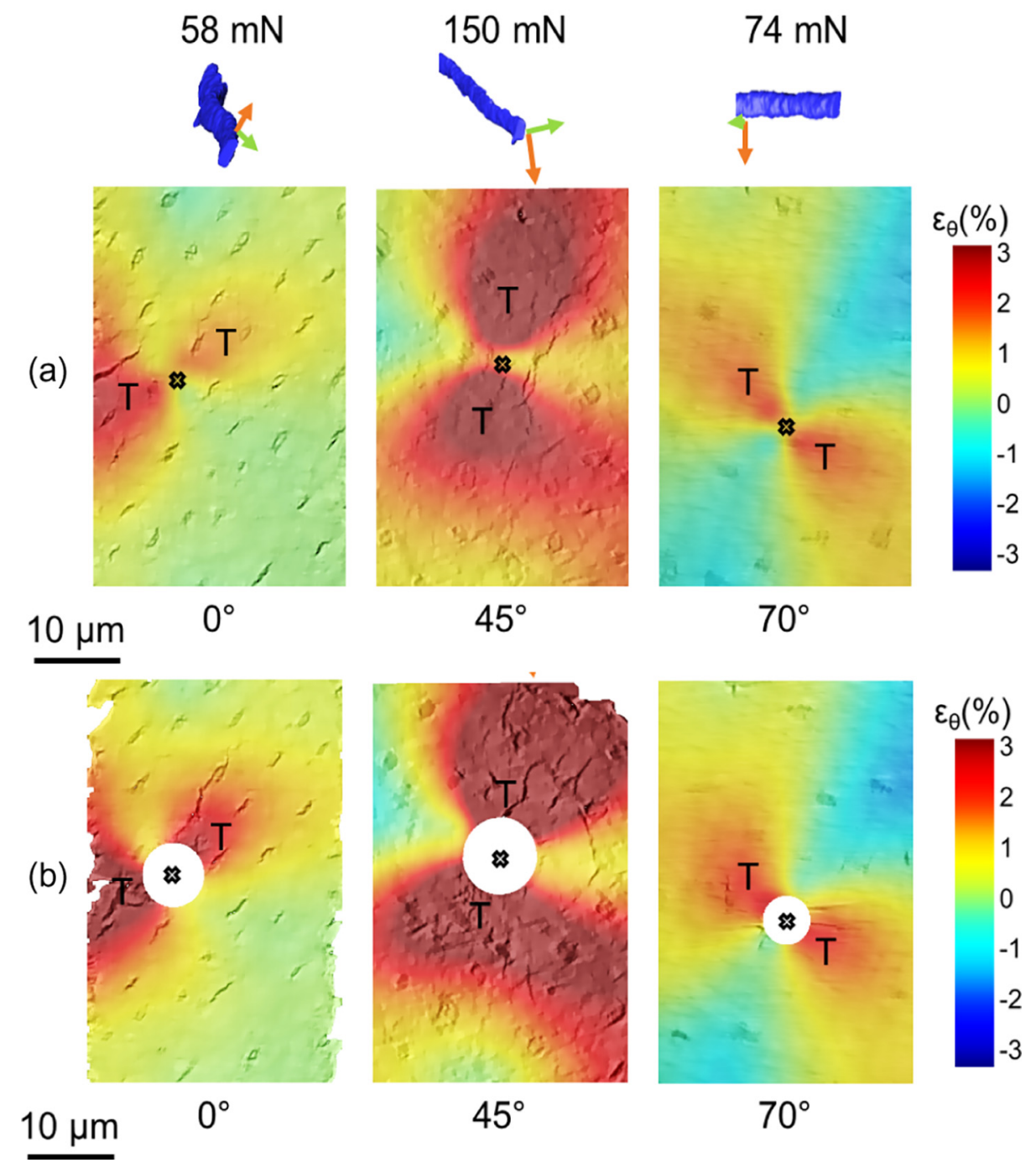

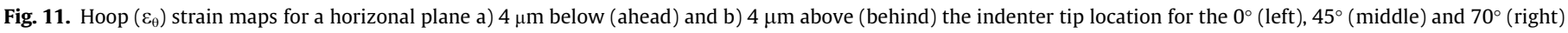

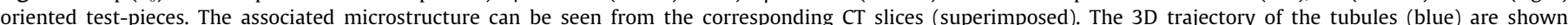

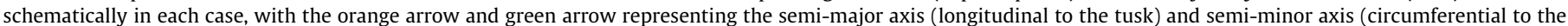
tusk) of the tubules respectively. (For interpretation of the references to colour in this figure legend, the reader is referred to the web version of this article.)

The crack propagation results indicate that cracks tend to be deflected towards the axial direction of the tusk. This is consistent with the function of the tusk: as elongated upper incisors they are mainly used for digging and carrying load. These activities impose substantial bending moment on the tusk, similar to those experienced by antlers and bones $[62,63]$. As a consequence, the collagen fibrils and tubules are arranged accordingly to provide significant axial strength and resistance to cracks perpendicular to the length of the tusk via deflection towards radial-axial of cracking, which is the least load-bearing direction. The findings in this work can also be extended to the study of anisotropic cracking and fracture analysis of archaeological bones in which the fissures are normally along the shaft direction and post mortem cracks produced by agencies or weather tend to align with the split-lines produced by punctures with a needle and decalcification [64].

\section{Conclusions}

This paper presents the first study of crack propagation in three dimensions at the nanoscale by time-lapse X-ray nano-CT. Crack propagation has been studied by indenting tusk at $0^{\circ}, 45^{\circ}$ and $70^{\circ}$ to the tubule axis. Several important conclusions can be drawn:

1. Both the axial alignment of collagen fibrils and the related tendency for microcracks to emanate in the axial direction from the radially aligned tubules within tusk lead to a very anisotropic crack propagation behaviour.

2. As the angle between the tubule axis and indentation axis increases the propensity for crack deflection and crack-tip shielding increases, moving from a small number of long cracks towards a network of smaller, and less threatening, cracks.

a. The $0^{\circ}$ test-piece with the tubules aligned with the indentation axis failed at the lowest stress with two dominant cracks; one in the axial-radial plane of the tusk linking up and following the line of the tubules, the other a shear crack crossing the radial tubules.

b. The test-piece oriented with the tubules at aligned $70^{\circ}$ showed many small cracks radial to the conical indenter at relatively low loads, but these penetrated relatively shallow depths before being diverted by the tubule/collagen at $70^{\circ}$. They did not propagate significantly with increased loading. 


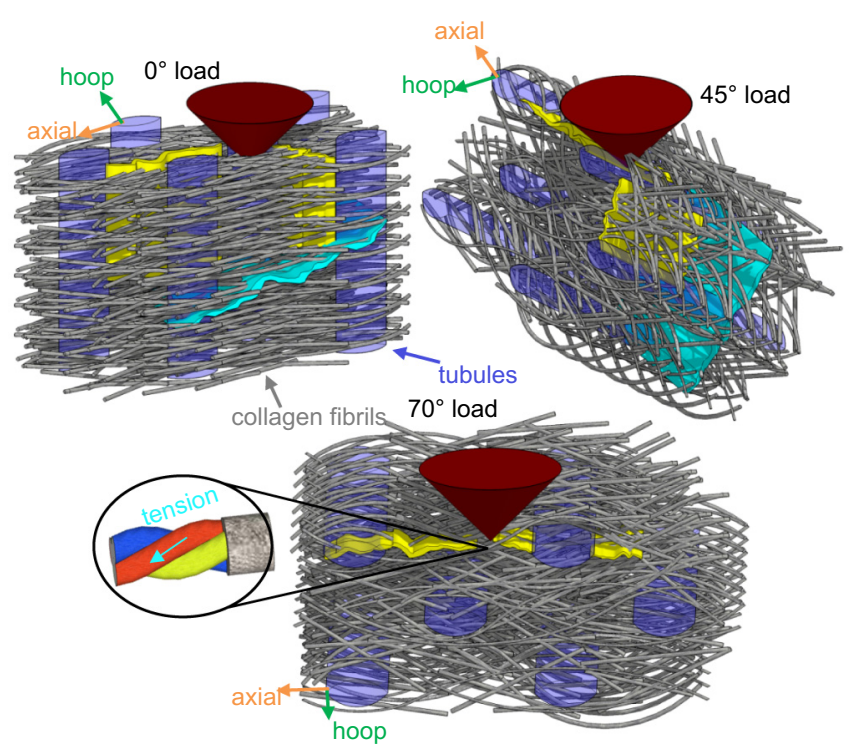

Fig. 12. Schematic diagram demonstrating the relative orientations of the collagen fibrils (grey) and thus tubules (blue) to the indenter tip for three test-pieces. The cracks in yellow and cyan colour correspond to axial cracks propagating along the major axis of the tubule cross sections (cleavage) and transversal cracks cutting across the longitudinal axes of the tubules due to the shear deformation. (For interpretation of the references to colour in this figure legend, the reader is referred to the web version of this article.)

c. The crack morphology of $45^{\circ}$ test-piece shows aspects of the $0^{\circ}$ and $70^{\circ}$ samples: many tiny cracks appeared early on, indicating a well-established sub-critical crack growth, followed by catastrophic failure through a large coalesced crack.

3. Strains well in excess of the $0.9 \%$ yield strain were recorded by digital volume correlation suggesting extensive plastic deformation. This was also evidenced by bending of the tubules.

4. Despite indentation by a conical indenter significant anisotropy in the hoop strain was recorded ahead of the indenter with lower strains recorded parallel to the collagen fibrils, while higher tensile hoop strains generally correlated with regions that go on to show significant cracking radial to the indenter as it penetrates further. For the $0^{\circ}$ and $45^{\circ}$ samples these cracks were associated mainly with cracking on a plane radial-axial to the tusk.

\section{Acknowledgements}

The authors wish to thankfully acknowledge all the staff in Henry Moseley X-ray Imaging Facility based in the University of Manchester within The Royce Institute (GR EP/R00661X/1) where the X-ray CT work was carried out and the Zeiss Global Centre at the University of Portsmouth for image post-processing and DVC analysis. We appreciate the help from Mr. Brian Daber and Prof. David Watts for their contribution to sample preparation. We are also grateful to the Engineering and Physical Science Research Council (EPSRC) grants EP/I02249X, EP/F007906 and EP/F028431 for funding the Henry Moseley X-ray Imaging Facility. The PI is grateful for an Advanced Grant from the European Research Council (CORREL-CT Grant 695638). The first author is grateful for China Scholarship Council and University of Manchester support. The elephant tusk used in present study was obtained legally from UK customs as a seizure against smuggling.

\section{References}

[1] R.K. Nalla, J.H. Kinney, R.O. Ritchie, Mechanistic fracture criteria for the failure of human cortical bone, Nat. Mater. 2 (3) (2003) 164.
[2] X. Lu, Characterisation of the anisotropic fracture toughness and crack-tip shielding mechanisms in elephant dentin $\mathrm{PhD}$ thesis, University of Manchester, 2015.

[3] D.D. Arola, R.K. Reprogel, Tubule orientation and the fatigue strength of human dentin, Biomaterials 27 (9) (2006) 2131-2140.

[4] D. Sykes, R. Hartwell, R.S. Bradley, T.L. Burnett, B. Hornberger, R.J. Garwood, P.J. Withers, Time-lapse three-dimensional imaging of crack propagation in beetle cuticle, Acta Biomater. 86 (2019) 109-116.

[5] D. Raabe, C. Sachs, P. Romano, The crustacean exoskeleton as an example of a structurally and mechanically graded biological nanocomposite material, Acta Mater. 53 (15) (2005) 4281-4292.

[6] A. Jackson, J.F. Vincent, R. Turner, The mechanical design of nacre, Proc. R. Soc. Lond. B Biol. Sci. 234 (1277) (1988) 415-440.

[7] F. Barthelat, H. Tang, P.D. Zavattieri, C.M. Li, H.D. Espinosa, On the mechanics of mother-of-pearl: a key feature in the material hierarchical structure, J. Mech. Phys. Solids 55 (2) (2007) 306-337.

[8] J.H. Kinney, M. Balooch, G.M. Marshall, S.J. Marshall, A micromechanics model of the elastic properties of human dentine, Arch. Oral Biol. 44 (10) (1999) 813822.

[9] S. Weiner, H.D. Wagner, The material bone: structure-mechanical function relations, Annu. Rev. Mater. Sci. 28 (1) (1998) 271-298.

[10] J.C. Halpin, Primer on Composite Materials Analysis, (Revised), CRC Press, 1992.

[11] D.E. Lieberman, Life history variables preserved in dental cementum microstructure, Science 261 (1993). 1162-1162.

[12] M. Albéric, M.N. Dean, A. Gourrier, W. Wagermaier, J.W. Dunlop, A. Staude, P. Fratzl, I. Reiche, Relation between the macroscopic pattern of elephant ivory and its three-dimensional micro-tubular network, PLoS ONE 12 (1) (2017) e0166671.

[13] M. Albéric, A. Gourrier, W. Wagermaier, P. Fratzl, I. Reiche, The threedimensional arrangement of the mineralized collagen fibers in elephant ivory and its relation to mechanical and optical properties, Acta Biomater. 72 (2018) $342-351$.

[14] X. Lu, S.D. Rawson, P.J. Withers, Effect of hydration and crack orientation on crack-tip strain, crack opening displacement and crack-tip shielding in elephant dentin, Dent. Mater. 34 (7) (2018) 1041-1053.

[15] M. Locke, Structure of ivory, J. Morphol. 269 (4) (2008) 423-450.

[16] R.K. Nalla, V. Imbeni, J.H. Kinney, M. Staninec, S.J. Marshall, R.O. Ritchie, In vitro fatigue behavior of human dentin with implications for life prediction, J. Biomed. Mater. Res. Part A 66A (1) (2003) 10-20.

[17] A.B. Moyes, D.W. Doidge, Composition of the mineral phase of dentin in southern elephant seal and antarctic fur-seal teeth, British Antarctic Survey Bull. 64 (1984) 81-84.

[18] A. Mills, Structural and Chemical Organization of Teeth, Elsevier, 2014.

[19] A.E.W. Miles, A. Boyde, Observations on Structure of Elephant Ivory, J. Anat. 95 (3) (1961) 450-1000.

[20] E.J. Raubenheimer, J. Dauth, M.J. Dreyer, P.D. Smith, M.L. Turner, Structure and composition of ivory of the African elephant (Loxodonta-Africana), S. Afr. J. Sci. 86 (4) (1990) 192-193.

[21] G.W. Marshall, N. Inai, I.C.W. Magidi, M. Ballouch, J.H. Kinney, J. Tagami, S.J. Marshall, Dentin demineralisation: effects of dentin depth, $\mathrm{pH}$ and different acids (vol 13, pg 338, 1997), Dent. Mater. 14 (5) (1998). 383383.

[22] R. Nalla, A. Porter, C. Daraio, A. Minor, V. Radmilovic, E. Stach, A. Tomsia, R. Ritchie, Ultrastructural examination of dentin using focused ion-beam crosssectioning and transmission electron microscopy, Micron 36 (7) (2005) 672 680.

[23] V. Jantou, M. Turmaine, G.D. West, M.A. Horton, D.W. McComb, Focused ion beam milling and ultramicrotomy of mineralised ivory dentine for analytical transmission electron microscopy, Micron 40 (4) (2009) 495-501.

[24] D. Arola, J.A. Rouland, D. Zhang, Fatigue and fracture of bovine dentin, Exp. Mech. 42 (4) (2002) 380-388.

[25] J. Ivancik, N.K. Neerchal, E. Romberg, D. Arola, The reduction in fatigue crack growth resistance of dentin with depth, J. Dent. Res. 90 (8) (2011) 1031-1036.

[26] N. Iwamoto, N.D. Ruse, Fracture toughness of human dentin, J. Biomed. Mater. Res. Part A 66A (3) (2003) 507-512.

[27] W. Bonfield, C.H. Li, Deformation and fracture of ivory, J. Appl. Phys. 36 (10) (1965) 3181-4000.

[28] J. Kruzic, R.K. Nalla, J.H. Kinney, R.O. Ritchie, Crack blunting, crack bridging and resistance-curve fracture mechanics in dentin: effect of hydration, Biomaterials 24 (28) (2003) 5209-5221.

[29] L.G. Watanabe, G.W. Marshall, S.J. Marshall, Dentin shear strength: effects of tubule orientation and intratooth location, Dent. Mater. 12 (2) (1996) 109115.

[30] D. Arola, R.K. Reprogel, Effects of aging on the mechanical behavior of human dentin, Biomaterials 26 (18) (2005) 4051-4061.

[31] K.J. Koester, J.W. Ager Iii, R.O. Ritchie, The effect of aging on crack-growth resistance and toughening mechanisms in human dentin, Biomaterials 29 (10) (2008) 1318-1328.

[32] N. Meredith, M. Sherriff, D.J. Setchell, S.A.V. Swanson, Measurement of the microhardness and young's modulus of human enamel and dentine using an indentation technique, Arch. Oral Biol. 41 (6) (1996) 539-545.

[33] L.H. He, N. Fujisawa, M.V. Swain, Elastic modulus and stress-strain response of human enamel by nano-indentation, Biomaterials 27 (24) (2006) 4388-4398.

[34] J.L. Cuy, A.B. Mann, K.J. Livi, M.F. Teaford, T.P. Weihs, Nanoindentation mapping of the mechanical properties of human molar tooth enamel, Arch. Oral Biol. 47 (4) (2002) 281-291. 
[35] D. Ziskind, M. Hasday, S.R. Cohen, H.D. Wagner, Young's modulus of peritubular and intertubular human dentin by nano-indentation tests, J. Struct. Biol. 174 (1) (2011) 23-30.

[36] M.S. Zafar, N. Ahmed, Nano-mechanical evaluation of dental hard tissues using indentation technique, World Appl. Sci. J. 28 (10) (2013) 1393-1399.

[37] Z.-j. Cheng, X.-m. Wang, J. Ge, J.-X. Yan, N. Ji, L.l. Tian, F.-z. Cui, The mechanical anisotropy on a longitudinal section of human enamel studied by nanoindentation, J. Mater. Sci.: Mater. Med. 21 (6) (2010) 1811-1816.

[38] L.E. Bertassoni, M.V. Swain, Influence of hydration on nanoindentation induced energy expenditure of dentin, J. Biomech. 45 (9) (2012) 1679-1683.

[39] D.J. Kim, M.H. Lee, D.Y. Lee, J.S. Han, Mechanical properties, phase stability, and biocompatibility of (Y, Nb)-TZP/Al2O3 composite abutments for dental implant, J. Biomed. Mater. Res. 53 (4) (2000) 438-443.

[40] M.A. Lopes, F.J. Monteiro, J.D. Santos, Glass-reinforced hydroxyapatite composites: fracture toughness and hardness dependence on microstructural characteristics, Biomaterials 20 (21) (1999) 2085-2090.

[41] G. Marshall, M. Balooch, R. Gallagher, S. Gansky, S. Marshall, Mechanical properties of the dentinoenamel junction: AFM studies of nanohardness elastic modulus, and fracture, J. Biomed. Mater. Res. 54 (1) (2001) 87-95.

[42] Z. Li, A. Ghosh, A.S. Kobayashi, R.C. Bradt, Indentation fracture toughness of sintered silicon carbide in the Palmqvist crack regime, J. Am. Ceram. Soc. 72 (6) (1989) 904-911.

[43] C.B. Ponton, R.D. Rawlings, Vickers indentation fracture toughness test Part 1 Review of literature and formulation of standardised indentation toughness equations, Mater. Sci. Technol. 5 (9) (1989) 865-872.

[44] A. Ghosh, Z. Li, C. Henager, A. Kobayashi, R. Bradt, Vickers microtoughness of $\mathrm{SiC}$ in the median-crack regime, Fracture Mech. Ceram. 11 (1995) 219-231.

[45] J. Kruzic, D. Kim, K. Koester, R. Ritchie, Indentation techniques for evaluating the fracture toughness of biomaterials and hard tissues, J. Mech. Behav. Biomed. Mater. 2 (4) (2009) 384-395.

[46] H.H.K. Xu, D.T. Smith, S. Jahanmir, E. Romberg, J.R. Kelly, V.P. Thompson, E.D. Rekow, Indentation damage and mechanical properties of human enamel and dentin, J. Dent. Res. 77 (3) (1998) 472-480.

[47] J. Baruchel, J.-Y. Buffiere, E. Maire, X-ray tomography in material science, (2000).

[48] E. Maire, P. Withers, Quantitative X-ray tomography, Int. Mater. Rev. 59 (1) (2014) 1-43.

[49] H.D. Barth, M.E. Launey, A.A. MacDowell, J.W. Ager III, R.O. Ritchie, On the effect of X-ray irradiation on the deformation and fracture behavior of human cortical bone, Bone 46 (6) (2010) 1475-1485.

[50] K.H. Khor, J.Y. Buffiere, W. Ludwig, H. Toda, H.S. Ubhi, P.J. Gregson, I. Sinclair, In situ high resolution synchrotron x-ray tomography of fatigue crack closure micromechanisms, J. Phys.-Condens. Matter 16 (33) (2004) S3511-S3515.
[51] A.I. Hussein, P.E. Barbone, E.F. Morgan, Digital volume correlation for study of the mechanics of whole bones, Procedia IUTAM 4 (2012) 116-125.

[52] F. Gillard, R. Boardman, M. Mavrogordato, D. Hollis, I. Sinclair, F. Pierron, M. Browne, The application of digital volume correlation (DVC) to study the microstructural behaviour of trabecular bone during compression, J. Mech. Behav. Biomed. Mater. 29 (2014) 480-499.

[53] D. Zhang, S. Mao, C. Lu, E. Romberg, D. Arola, Dehydration and the dynamic dimensional changes within dentin and enamel, Dent. Mater. 25 (7) (2009) 937-945.

[54] B.M. Patterson, N.L. Cordes, K. Henderson, J.C.E. Mertens, A.J. Clarke, B. Hornberger, A. Merkle, S. Etchin, A. Tkachuk, M. Leibowitz, D. Trapp, W. Qiu, B. Zhang, H. Bale, X. Lu, R. Hartwell, P.J. Withers, R.S. Bradley, In situ laboratorybased transmission X-ray microscopy and tomography of material deformation at the nanoscale, Exp. Mech. 56 (9) (2016) 1585-1597.

[55] Y. Sagara, A.K. Hara, W. Pavlicek, A.C. Silva, R.G. Paden, Q. Wu, Abdominal CT: comparison of low-dose CT with adaptive statistical iterative reconstruction and routine-dose CT with filtered back projection in 53 patients, Am. J. Roentgenol. 195 (3) (2010) 713-719.

[56] G. Lauritsch, W.H. Härer, Theoretical framework for filtered back projection in tomosynthesis, Medical Imaging'98, Int. Soc. Opt. Photonics (1998) 1127-1137.

[57] M. Peña Fernández, S. Cipiccia, E. Dall'Ara, A.J. Bodey, R. Parwani, M. Pani, G.W. Blunn, A.H. Barber, G. Tozzi, Effect of SR-microCT radiation on the mechanical integrity of trabecular bone using in situ mechanical testing and digital volume correlation, J. Mech. Behav. Biomed. Mater. 88 (2018) 109-119.

[58] G. Tozzi, V. Danesi, M. Palanca, L. Cristofolini, Elastic full-field strain analysis and microdamage progression in the vertebral body from digital volume correlation, Strain 52 (5) (2016) 446-455.

[59] M. Peña Fernández, A.H. Barber, G.W. Blunn, G. Tozzi, Optimization of digital volume correlation computation in SR-microCT images of trabecular bone and bone-biomaterial systems, J. Microsc. 272 (3) (2018) 213-228.

[60] L. Liu, E.F. Morgan, Accuracy and precision of digital volume correlation in quantifying displacements and strains in trabecular bone, J. Biomech. 40 (15) (2007) 3516-3520.

[61] J. Kinney, J. Pople, G. Marshall, S. Marshall, Collagen orientation and crystallite size in human dentin: a small angle X-ray scattering study, Calcif. Tissue Int. 69 (1) (2001) 31-37.

[62] P. Fratzl, S. Schreiber, A. Boyde, Characterization of bone mineral crystals in horse radius by small-angle X-ray scattering, Calcif. Tissue Int. 58 (5) (1996) $341-346$.

[63] M.E. Launey, P.-Y. Chen, J. McKittrick, R. Ritchie, Mechanistic aspects of the fracture toughness of elk antler bone, Acta Biomater. 6 (4) (2010) 1505-1514.

[64] N.C. Tappen, The relationship of weathering cracks to split-line orientation in bone, Am. J. Phys. Anthropol. 31 (2) (1969) 191-197. 